\title{
Modification of internal hernia classification system after laparoscopic Roux-en-Y bariatric surgery
} \author{
Markus Zimmermann ${ }^{1}$, August Kuehling ${ }^{1}$, Jodok Fink ${ }^{5}$ \\ ${ }^{1}$ Department of Surgery, Schleswig-Holstein University Clinic, Campus Lübeck, Lübeck, Germany \\ ${ }^{2}$ Department of Hepatobiliary Surgery, Wuhan No. 1 Hospital, Wuhan, China \\ ${ }^{3}$ Obesity Clinic Queensland, Brisbane, Australia \\ ${ }^{4}$ Department of Surgery, Jagiellonian University Medical College, Krakow, Poland \\ ${ }^{5}$ Department of Surgery, University of Freiburg, Freiburg, Germany
}

W. Konrad Karcz ${ }^{1}$, Cheng Zhou ${ }^{2}$, Mark Daoud ${ }^{3}$, Zhao Gong ${ }^{2}$, Katarzyna Blazejczyk ${ }^{1}$, Tobias Keck ${ }^{1}$, Maciej Matlok ${ }^{4}$,

Videosurgery Miniinv 2015; 10 (2): 197-204 DOI: $10.5114 /$ wiitm.2015.52160

\begin{abstract}
Introduction: The occurrence of internal hernia is not an uncommon late complication following the laparoscopic bariatric Roux-en-Y gastric bypass procedure. In some instances, it can be life threatening if not treated in a timely manner. Although there are numerous publications in the literature addressing internal hernia, they are mostly retrospective, and focus mainly on describing the different reconstructive orientation as far as the bowel is concerned. Aim: Our study aim is to address the relationship between the three basic elements of internal hernia, namely: intestinal mesentery defect, the involved intestine and herniated loop direction. Although a developed and widely accepted classification system of internal hernia has not been established yet, we hope this study can help the system to be established.

Material and methods: We studied all patients who underwent revision bariatric operations in the Freiburg and Lübeck University Hospitals (2007-2013). A single surgeon performed and documented all revision procedures for internal hernia. The post-operative follow-up period is up to 6 years. All patients with internal hernias were included whether their primary surgery was performed in our center or performed in other institutions, being referred to our center for further management. The presence of hernia defect, the type of herniated intestinal loop and the direction by which the herniated intestinal loop migrated were analyzed.

Results: Twenty-five patients with internal hernia were identified; in 2 patients more than one hernia type coexisted. The most frequent constellation of internal hernias was BP limb herniation into the Brolin space and migrating from left to right direction (28\%). The highest incidence of internal hernia was found to be following Roux-en-Y gastric bypass (68\%); the biliopancreatic limb (BP) limb was the most commonly involved intestine (51.9\%). The incidence of Petersen hernia was the highest (59.3\%), and left-right direction was more common. The most common hernia direction of the biliopancreatic limb was from left to right (92.6\%), but alimentary limb (AL; 57.1\%) and common channel (CC; 66.7\%) often favor the other course.

Conclusions: There are existing different types of internal hernias after bariatric operations including separate mesenterial spaces, various intestine parts and herniation direction. Our SDL classification system may offer a useful pathway that facilitates the understanding, and systematic approach to internal hernia, which can be used by bariatric quality registers.
\end{abstract}

Key words: internal hernia classification system, internal hernia, bariatric surgery, Petersen space, Brolin space.

\section{Address for correspondence}

Prof. Wojciech Konrad Karcz MD, PhD, Department of Surgery, Schleswig-Holstein University Clinic, Campus Lübeck,

Ratzebeurger Alle 160, 23562 Lübeck, Germany, phone: +49 4515005858, fax: +49 4515003989, e-mail: konrad.karcz@uksh.de 


\section{Introduction}

In 1900, Petersen [1] was the first surgeon to report an internal hernia after gastrojejunostomy. Since then, as a recognized complication secondary to procedures such as gastric tumor surgery, bariatric surgery, and liver transplantation, the internal hernia has become gradually well known. Incidence of internal hernia resulting from laparoscopic bariatric operations is obviously greater than its open counterpart [2]. After laparoscopic Roux-en-Y gastric bypass (RYGB), the incidence is about 0.5-9.0\% [2-4]. Instead of peritoneal adhesion being the leading cause of small bowel obstruction following conventional open surgery, internal hernia is responsible for more small bowel obstructions (SBOs) following laparoscopic operations. The symptoms of internal hernia are variable; the sensitivity of imaging remains only $64 \%$ [5], and the computed tomography (CT) misdiagnosis rate of internal hernia is as high as 20\% [6]. This often impedes accurate diagnosis, which leads to deterioration of the patient's condition.

\section{Material and methods}

\section{Patient collection}

Between 2007 and 2013, 25 consecutive patients with internal herniation were recruited after Roux-en-Y reconstructions in our revisionary surgery cohort in the Freiburg and Lübeck University Obesity Centres. Patients were divided into two groups. The first group included patients with primary bariatric procedures performed in Freiburg University Hospital (primary group - PG). The patients whose primary bariatric procedures were performed in other sur-

Table I. Incidence of internal hernia in 144 patients, following Roux-en-Y reconstruction in Freiburg and Lübeck University Hospitals (20072013)

\begin{tabular}{|lc|}
\hline Category & Patients, $n$ (\%) \\
\hline Recruited & 144 \\
\hline Post-operative internal hernia & $25(17.4)$ \\
\hline Primary group & $11(7.6)$ \\
\hline Secondary group & $14(9.7)$ \\
\hline Female & $28(90.3)$ \\
\hline Male & $3(9.7)$ \\
\hline
\end{tabular}

gical institutes were assigned to the second group (secondary group - SG). The reasons for admission to the university center were postoperative complications following a bariatric procedure, with the aim of further management in a tertiary referral center. All revisionary cases were operated on by the same surgeon. The indications for surgical intervention were persistent abdominal pain or acute symptomatic ileus. All patients in the primary group (operated on in the University of Freiburg) were already enrolled in an obesity follow-up program. The program also emphasized any complications secondary to bariatric procedures. This will obviously include the various forms of internal herniation as well as trocar herniation.

\section{Data collection}

Combined with operative and postoperative reports, the data of patients were collected and submitted by the bariatric surgeon and interdisciplinary team in the outpatient clinic. Data retrieval was performed with the Prometheus system.

\section{Results}

The total incidence of internal hernias among revisionary bariatric surgery procedures was $7.6 \%$. In comparison the hernia incidence should be quite similar in both groups. The herniation rate was higher in female patients (90.3\%) but the female/male index in our bariatric surgery center was 1.86. The mean duration between laparoscopic Roux-en-Y reconstruction and re-operation for internal hernia was about 24 months (Table I).

There were 2 patients in the primary group (no. 8 and no. 10) in whom more than one type of internal hernia coexisted. In each scenario, the Petersen (retro alimentary limb) and Brolin (retro enteroenterostomy) space were both herniated by two different bowel limbs with migration in a completely opposite direction (Table II). Likewise, the secondary group had two cases of coexisting internal hernias (no. 13 and no. 21), which also involved two different bowel limbs traveling in opposite directions, but associated only with the Petersen space (Tables III and IV).

In our series the most frequent bariatric procedure that was followed by postoperative internal hernia was gastric bypass (17/68\%), followed by biliopancreatic diversion (BPD) with an incidence of $28 \%$. After bariatric procedures with Roux-en-Y re- 
constructions, the incidence of Petersen herniation was the highest (16/59.3\%), prevalent especially in patients who came to our center with severe abdominal pain (71.4\%).

The most frequently involved limb was BPL herniate through Brolin space to right lower abdominal quadrant (7/28\%) (Figure 1 ), followed by BPL through Petersen space in the same direction (6/24\%) (Figure 2) space from left to right into lower abdominal quadrant. After gastric bypass (GBP), the incidence of Brolin space (57.9\%) and Petersen space hernia $(42.1 \%)$ were similar, but BPDs only lead to Peterson herniation type complication in both groups. In Duodeno-Ileo Omega Switch (DIOS) there is only the option for Petersen space herniation because of B2 reconstruction [7]. 51.9\% of hernias involved the BPL. The alimentary limb was affected in $25.9 \%$, but the frequency was much higher in the SG in comparison to the PG, with $35.7 \%$ and $15.3 \%$ respectively. Alimentary limb $(\mathrm{AL})$ herniation through the Petersen space (PS) is not uncommon (7/43.8\%) (Figure 3), but no $\mathrm{AL}$ limb reached the Brolin space in any direction in spite of its theoretical feasibility (Figure 4). The PS was associated with more frequent alimentary limb hernia (up to 43.8\%), while the Brolin space (BS) more often affected the biliopancreatic limb (72.7\%).

The analysis of the course that the herniated small bowel loop took attracted our attention, with the left-right (L/R) herniation(14/56\%) being more common than the right-left (R/L) $(9 / 36 \%)$. In the primary group the ratio of $L / R$ to $R / L$ was 8 to 1 , but in the SG it was 3 to 4 . For the BS type herniation, left-right directions could be identified in $63.6 \%$ of cases, and were more frequent in the PG (71.4\%). According to our observation, the favorite herniation course of the biliopancreatic limb is from left to right (13/92.6\%), but AL (4/57.1\%) and CC (4/66.7\%) prefer to take the opposite direction.

\section{Discussion}

The effectiveness of bariatric surgery in obesity management has led to an increase in the number of operations performed by $761 \%$ in the last 10 years. Consequently a rising number of complications is inevitable. Internal hernias are important late complications. In 1900 Petersen [1] described hernia after GE, and in 1972 Petersen [8] described the Treitz hernia. Brolin [9] described small bowel obstruction (SBO) due to bariatric procedures as
Table II. Consecutive cases of postoperative internal hernias and different Roux-en-Y reconstructions

\begin{tabular}{|c|c|c|c|c|c|}
\hline No. & Op & Hernia & Direction & $\begin{array}{l}\text { Herniated } \\
\text { intestine }\end{array}$ & Gender \\
\hline \multicolumn{6}{|c|}{ Primary group: } \\
\hline 1 & CRYGB & Retro-AL & $\mathrm{L} / \mathrm{R}$ & $\mathrm{BPL}$ & $\mathrm{F}$ \\
\hline 2 & CRYGB & Retro-EEA & $\mathrm{L} / \mathrm{R}$ & $\mathrm{BPL}$ & $\mathrm{F}$ \\
\hline 3 & CRYGB & Retro-EEA & $\mathrm{L} / \mathrm{R}$ & $\mathrm{BPL}$ & $\mathrm{F}$ \\
\hline 4 & BDP-DS & Retro-AL & $\mathrm{L} / \mathrm{R}$ & $\mathrm{BPL}$ & $\mathrm{F}$ \\
\hline 5 & CRYGB & Retro-EEA & $\mathrm{L} / \mathrm{R}$ & $\mathrm{BPL}$ & $\mathrm{F}$ \\
\hline 6 & CRYGB & Retro-EEA & $R / L$ & $\mathrm{CC}$ & $\mathrm{F}$ \\
\hline 7 & BRYGB & Retro-EEA & $\mathrm{L} / \mathrm{R}$ & $\mathrm{BPL}$ & $\mathrm{F}$ \\
\hline 8 & CRYGB & Both & $L / R+R / L$ & $\mathrm{BPL}+\mathrm{CC}$ & $\mathrm{F}$ \\
\hline 9 & CRYGB & Retro-AL & $\mathrm{L} / \mathrm{R}$ & $\mathrm{BPL}$ & $\mathrm{F}$ \\
\hline 10 & BRYGB & Both & $\mathrm{R} / \mathrm{L}+\mathrm{L} / \mathrm{R}$ & $A L+B P L$ & $M$ \\
\hline 11 & DIOS-SG & Retro-AL & $\mathrm{L} / \mathrm{R}$ & $\mathrm{AL}$ & $\mathrm{F}$ \\
\hline \multicolumn{6}{|c|}{ Secondary group: } \\
\hline 12 & CRYGB & Retro-EEA & $\mathrm{L} / \mathrm{R}$ & $\mathrm{BPL}$ & $\mathrm{F}$ \\
\hline 13 & BPD & Retro-AL & $R / L$ & $A L+C C$ & $\mathrm{~F}$ \\
\hline 14 & BPD-DS & Retro-AL & $R / L$ & $\mathrm{AL}$ & $\mathrm{F}$ \\
\hline 15 & BPD-DS & Retro-AL & $\mathrm{L} / \mathrm{R}$ & $A L$ & $\mathrm{~F}$ \\
\hline 16 & CRYGB & Retro-EEA & $R / L$ & $\mathrm{BPL}$ & $\mathrm{F}$ \\
\hline 17 & CRYGB & Retro-AL & $R / L$ & $C C$ & $\mathrm{~F}$ \\
\hline 18 & CRYGB & Retro-AL & $\mathrm{L} / \mathrm{R}$ & $\mathrm{BPL}$ & $\mathrm{F}$ \\
\hline 19 & BPD-DS & Retro-AL & $R / L$ & $\mathrm{AL}$ & $M$ \\
\hline 20 & BPD & Retro-AL & $\mathrm{L} / \mathrm{R}$ & $\mathrm{AL}$ & $M$ \\
\hline 21 & BPD & Retro-AL & $R / L$ & $\mathrm{CC}+\mathrm{AL}$ & $\mathrm{F}$ \\
\hline 22 & CRYGB & Retro-AL & $R / L$ & $\mathrm{AL}$ & $\mathrm{F}$ \\
\hline 23 & CRYGB & Retro-AL & $\mathrm{L} / \mathrm{R}$ & $\mathrm{BPL}$ & $\mathrm{F}$ \\
\hline 24 & CRYGB & Retro-EEA & $\mathrm{L} / \mathrm{R}$ & $\mathrm{BPL}$ & $\mathrm{F}$ \\
\hline 25 & BRYGB & Retro-EEA & $R / L$ & $\mathrm{CC}$ & $\mathrm{F}$ \\
\hline
\end{tabular}

CRYGB - Conventional Roux-en-Y bypass, BRYGB - banded Roux-en-Y gastric bypass, BPD - biliopancreatic division, BPD-DS - duodenal switch, DIOS-SG - duodeno-ileo omega switch with sleeve gastrectomy, retro-EEA - retro enteroenterostomy (Brolin space), Retro-AL - retro alimentary limb (Petersen space), $L / R$ - from left to right, $R / L$ - from right to left, $A L$ - alimentary limb, $B P L$ - biliopancreatic limb, CC - common channel.

a potential life-threatening situation and proposed a special suture technique to avoid SBO after enteroenterostomy. Both names are linked to the ana- 
Table III. General mutual relationship list regarding Operation Type, Herniated Intestine, Petersen/Brolin type and Hernia direction

\begin{tabular}{|c|c|c|c|c|}
\hline Category & Primary group, $n(\%)$ & Secondary group, $n(\%)$ & \multicolumn{2}{|c|}{ Sum, $n(\%)$} \\
\hline \multicolumn{5}{|c|}{ Internal hernia and OP type: } \\
\hline CRYGB & $7(63.6)$ & $7(50)$ & & \\
\hline BRYGB & $2(18.2)$ & $1(7.14)$ & & \\
\hline BPD & $0(0)$ & $3(21.4)$ & GBP & $17(68)$ \\
\hline BPD-DS & $1(9.1)$ & $3(21.4)$ & $\mathrm{BPD}$ & $7(28)$ \\
\hline DIOS-SG & $1(9.1)$ & $0(0)$ & DIOS & $1(4)$ \\
\hline \multicolumn{5}{|c|}{ Internal hernia and herniated intestine: } \\
\hline $\mathrm{BPL}$ & $9(69.2)$ & $5(35.7)$ & $\mathrm{BPL}$ & $14(51.9)$ \\
\hline $\mathrm{AL}$ & $2(15.3)$ & $5(35.7)$ & AL & $7(25.9)$ \\
\hline $\mathrm{CC}$ & $2(15.3)$ & $2(14.3)$ & $\mathrm{CC}$ & $4(14.8)$ \\
\hline$A L+C C$ & $0(0.0)$ & $2(14.3)$ & $\mathrm{AL}+\mathrm{CC}$ & $2(7.4)$ \\
\hline \multicolumn{5}{|c|}{ Internal hernia and Petersen/Brolin type: } \\
\hline Petersen & $4(36.4)$ & $10(71.4)$ & Petersen & $14(56)$ \\
\hline Brolin & $5(45.5)$ & $4(28.6)$ & Brolin & $9(36)$ \\
\hline Petersen + Brolin & $2(18.2)$ & $0(0)$ & Petersen + Brolin & $2(8)$ \\
\hline \multicolumn{5}{|c|}{ Internal hernia and hernia direction: } \\
\hline$L / R$ & $8(72.7)$ & $6(42.9)$ & $L / R$ & $14(56)$ \\
\hline $\mathrm{R} / \mathrm{L}$ & $1(9.1)$ & $8(57.1)$ & $R / L$ & $9(36)$ \\
\hline$L / R+R / L$ & $2(18.2)$ & $0(0.0)$ & $L / R+R / L$ & $2(8)$ \\
\hline
\end{tabular}

tomical changes after Roux-en-Y reconstruction. The understanding and management of internal hernia is worth further study and discussion.

Higa et al. [10, 11] found that the laparoscopic intervention had advantages such as less wound infection, minimized postoperative pain, better operative vision, and reduced abdominal adhesion. Meyer et al. [12, 13] believes that the rapid weight loss after bariatric procedures will lead to enlargement of the peritoneal cavity. These two aspects of laparoscopic surgery are the key risk factors for postoperative internal hernia formation after bariatric surgery. Champion and Williams [14] reported that the incidence of internal hernia after anterior-colon procedures is about $4.5 \%$, compared with the rate of $2.4 \%$ in Brolin's publication [10].

In our follow-up data, the incidence of internal hernia in primary bariatric procedures was $7.6 \%$. The incidence of primary cases could only be estimated because the follow-up rate was about 53\%, which was caused by overwhelmed regional Institution work. Brolin's [10] data demonstrate that the average duration for post-RYGB patients to reach the lowest point of their bodyweight is 18 to 24 months, so only with at least such length of follow-up should internal hernia incidence be estimated. In our series, the average follow-up matches the standard of 24 months, probably contributing to our high incidence.

Rodríguez et al. [15] reported that SBO incidence resulting from internal hernia after bypass is $1-11 \%$, but according to Champion and William's [14] data, it is only $0.43 \%$. Our observation shows that, after laparoscopic bariatric Roux-en-Y reconstructions with the ante-colonic approach, only 2 patients received an emergency operation due to SBO. Both of them were associated with herniating enteroenterostomy. We could not accurately ascertain the incidence 
Table IV. Specific relationship regarding localization and hernias direction

\begin{tabular}{|c|c|c|c|c|c|c|}
\hline Category & \multicolumn{2}{|c|}{ Primary group, $n(\%)$} & \multicolumn{2}{|c|}{ Secondary group, $n(\%)$} & \multicolumn{2}{|c|}{ Sum, $n(\%)$} \\
\hline \multicolumn{7}{|c|}{ Petersen/Brolin type and OP type: } \\
\hline & Petersen & Brolin & Petersen & Brolin & Petersen & Brolin \\
\hline GBP & $4(36.4)$ & $7(63.6)$ & $4(50)$ & $4(50)$ & $8(42.1)$ & $11(57.9)$ \\
\hline $\mathrm{BPD}$ & $1(100)$ & 0 & $6(100)$ & 0 & $7(100)$ & $0(0)$ \\
\hline DIOS & $1(100)$ & N/A & 0 & N/A & $1(100)$ & $N / A$ \\
\hline \multicolumn{7}{|c|}{ Petersen/Brolin type and hernia direction: } \\
\hline & Petersen & Brolin & Petersen & Brolin & Petersen & Brolin \\
\hline$L / R$ & $5(83.3)$ & $5(71.4)$ & $4(40)$ & $2(50)$ & $9(56.3)$ & $7(63.6)$ \\
\hline$R / L$ & $1(16.7)$ & $2(28.6)$ & $6(60)$ & $2(50)$ & $7(43.7)$ & $4(36.4)$ \\
\hline \multicolumn{7}{|c|}{ Petersen/Brolin type and herniated intestine: } \\
\hline & Petersen & Brolin & Petersen & Brolin & Petersen & Brolin \\
\hline $\mathrm{BPL}$ & $4(66.7)$ & $5(71.4)$ & $2(20)$ & $3(75)$ & $6(37.5)$ & $8(72.7)$ \\
\hline$A L$ & $2(33.3)$ & 0 & $5(50)$ & 0 & $7(43.8)$ & $0(0)$ \\
\hline $\mathrm{CC}$ & $0(0)$ & $2(28.6)$ & $1(10)$ & $1(25)$ & $1(6.3)$ & $3(27.3)$ \\
\hline $\mathrm{AL}+\mathrm{CC}$ & 0 & 0 & $2(20)$ & 0 & $2(12.5)$ & $0(0)$ \\
\hline \multicolumn{7}{|c|}{ Herniated intestine and hernia direction: } \\
\hline & $L / R$ & $R / L$ & $L / R$ & $R / L$ & $L / R$ & $R / L$ \\
\hline $\mathrm{BPL}$ & $9(100)$ & 0 & $4(80)$ & $1(20)$ & $13(92.6)$ & $1(7.4)$ \\
\hline$A L$ & $1(50)$ & $1(50)$ & $2(40)$ & $3(60)$ & $3(42.9)$ & $4(57.1)$ \\
\hline$C C$ & $2(100)$ & $0(0)$ & $0(0)$ & 2 (100) & $2(33.3)$ & $4(66.7)$ \\
\hline$A L+C C$ & $0(0)$ & $0(0)$ & $0(0)$ & $2(100)$ & $0(0)$ & $2(100)$ \\
\hline
\end{tabular}

because both patients came to our department as emergency cases and underwent their primary procedure elsewhere.

O'Rourke's [16] data indicate that, in Petersen type internal hernia, the most commonly involved limbs are the BPL and $A L$, and left to right is the most prevalent hernia direction. It means, according to our proposed classification system (Table V), that the type of P-R-B (Space: Petersen-Direction: Right to Left-Limb: Biliopancreatic) and P-R-A (Space: Petersen-Direction: Right to Left-Limb: Alimentary) is most frequently found. When summing up with our two study groups, BPL is the most involved limb (51.9\%), AL the second most common with the rate of $25.9 \%$, and left to right direction $(56.3 \%)$ is preponderant in Petersen type; these characters are in accordance with O'Rourke's publication. In our study, what is different from that, there is more $\mathrm{AL}$ (43.8\%) involved in Petersen, and BPL (72.7\%). We believe that the reasons for high frequency of Brolin space associated with BPL and Petersen space with $\mathrm{AL}$ are the same. Additionally, we were surprised that there was not even one case with the alimentary limb projected into the Brolin space, although it is theoretically possible. This phenomenon might be related to the wider distance between the Brolin space and alimentary limb due to the effect of gravity on the small intestine caused by the erect position [17].

There are divergent data about the incidence of Petersen and Brolin hernias. Koppmann et al. [18] depicted a higher occurrence of Petersen (56\%) than Brolin herniation (44\%). Contrarily, Lannelli et al. $[19,20]$ believes that the Brolin space is prone to be 


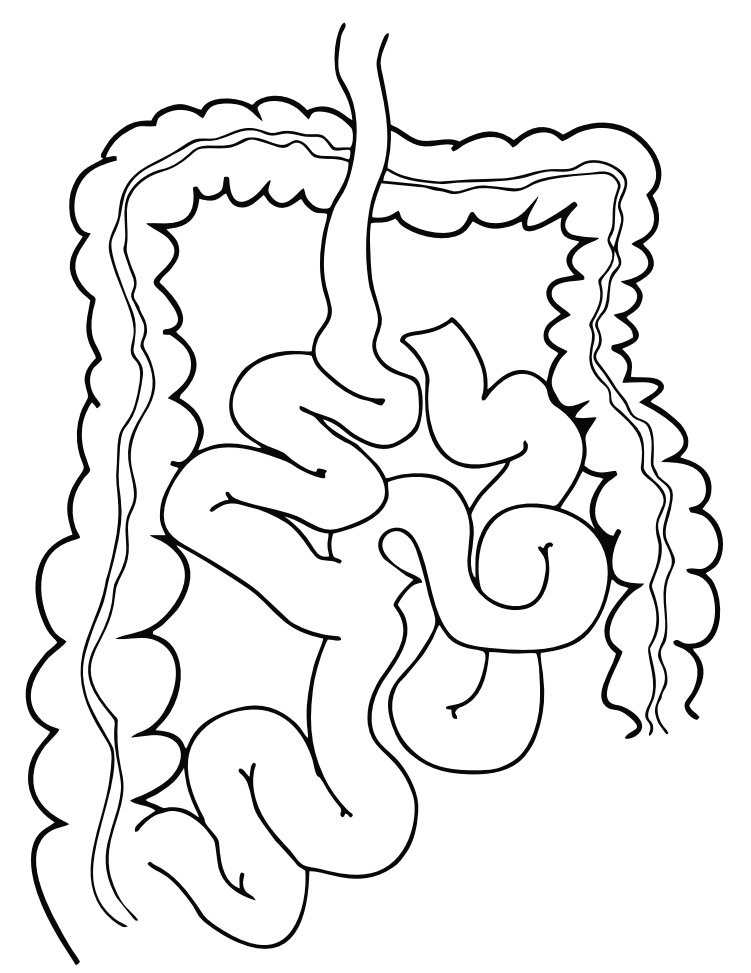

Figure 1. B-R-B type by SDL classification system

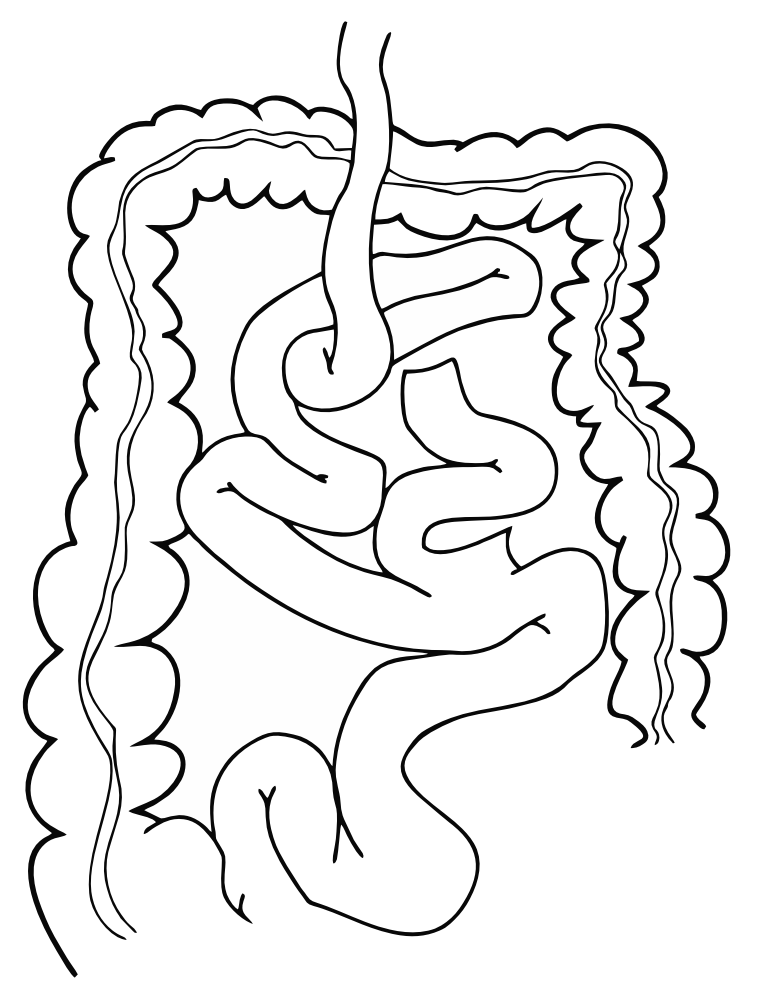

Figure 3. P-L-A type by SDL classification system

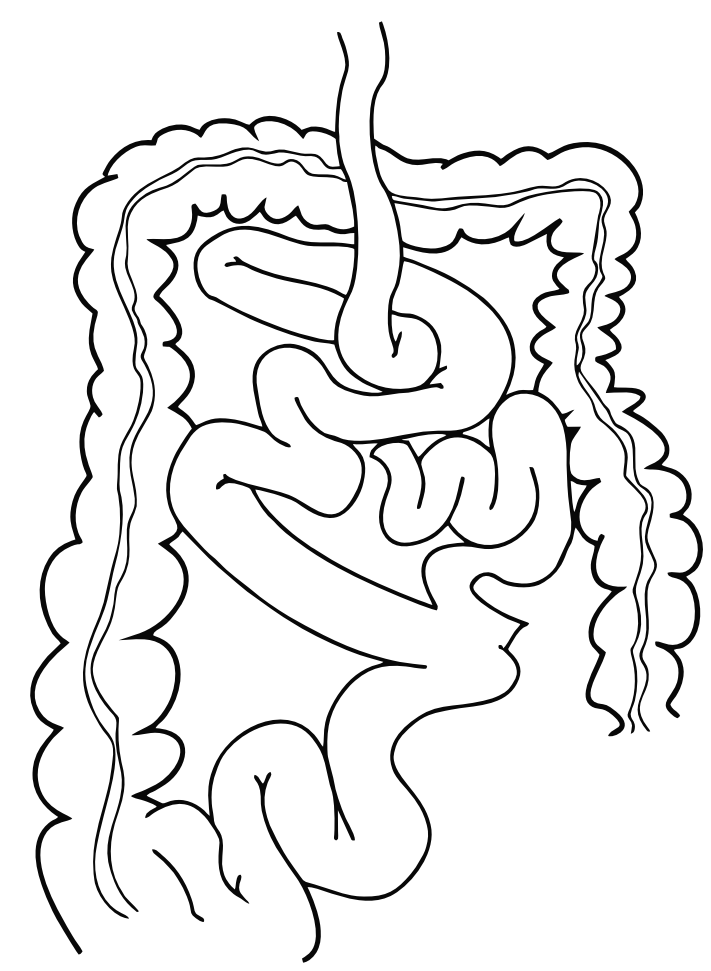

Figure 2. P-R-A type by SDL classification system

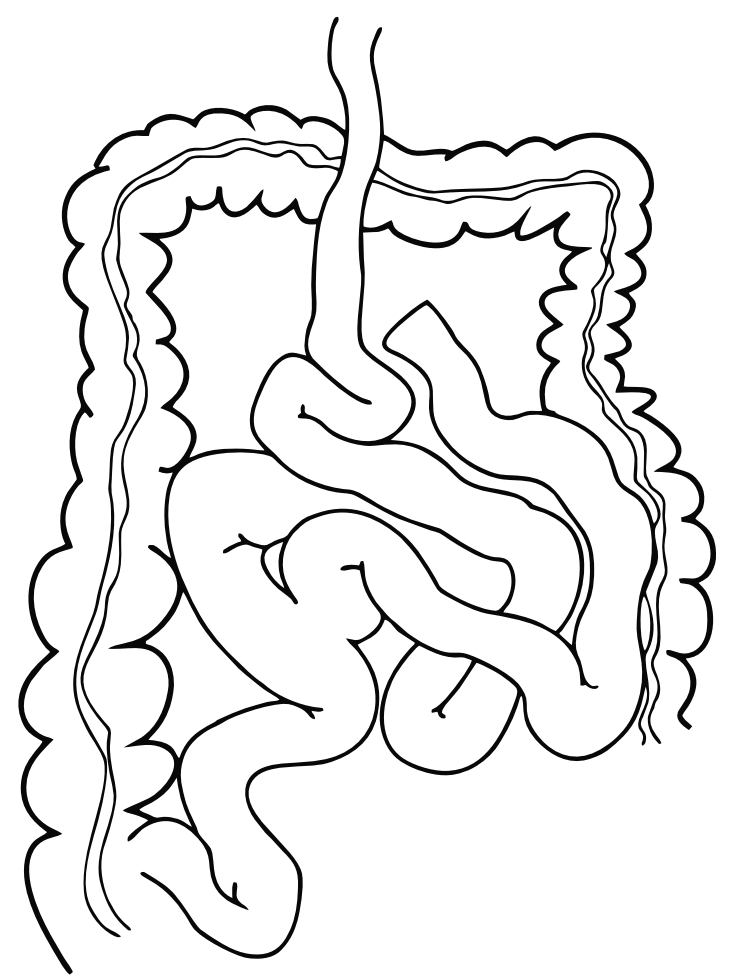

Figure 4. B-R-A type by SDL classification system 
herniated, because gravity facilitates the intestine projection into the space with a lower position. Our data showed that, after gastric bypass, the general rates of Petersen and Brolin hernia were similar in total, in the primary and in the secondary group: $8 / 11$, $4 / 7$ and $4 / 4$ respectively. These data are consistent with Lannelli's results. Both mesentery closures by bypass procedure are difficult to perform because of colon transversum behind $\mathrm{AL}$ and very low location of mesentery fault behind enteroenterostomy by upper Gl surgery. We noticed another interesting phenomenon that after BPD(-DS) the herniation were located in Petersen, but no Brolin space [7].

The suspected reasons include the procedures themselves: first the continuity of the small intestine was restored far from the GE anastomosis, which leads to the surgeon's position switching to the left side; second because of the operation field view the trocar positions are more distal (lower) compared to GBP. By duodeno-ileo omega switch the reason is obvious.

For better clinical communication and registers surgeons classified the post-operative internal hernias in different ways. Meyer et al. [12] used the locations that hernias occupied in the peritoneal cavity as a scale to catalogue, but the involved limbs are kept unknown. Tucker et al. [21] developed an ABC system based on involved limbs. The simply constructed system has A as the alimentary limb, and B and $C$ as the biliopancreatic limb and common channel respectively. The $A B C$ System did not concern in which location and from which direction the limbs herniated. These limits are inconvenient for understanding of pathology in internal hernia, and communication between bariatric and non-bariatric physicians.

With those concerns in mind, we would like to propose a new classification: the Space-Direction-Limb (SDL) Classification System (Table V).

We defined Petersen space and Brolin space as $P$ and $B$, herniating from right to left as $R / L$ and left to right as $L / R$, and simplified the involved alimentary limb/biliopancreatic limb/common channel as $A \& B \& C$ according to Tucker, and we added $E$ for the enteroenterostomy when herniation contentsit. The letter $\mathrm{E}$ was at the beginning used only as the abbreviation for enteroenterostomy, but after the analysis of acute operations we enlarged it to include emergency. With this method, we listed all possible types of internal hernias; it helps not only in clinical un-
Table V. Space-Direction-Limb (SDL) classification system for internal hernias secondary to ante-colic bariatric Roux-en-Y reconstruction in our institution

\begin{tabular}{|lcccc|}
\hline Variable & \multicolumn{2}{c}{$\mathrm{P}$} & \multicolumn{2}{c|}{$\mathrm{B}$} \\
\cline { 2 - 5 } & $\mathrm{L}(\%)$ & $\mathrm{R}(\%)$ & $\mathrm{L}(\%)$ & $\mathrm{R}(\%)$ \\
\hline $\mathrm{A}(\mathrm{AL})$ & $4(16)$ & $3(12)$ & $\mathrm{N} / \mathrm{A}$ & $0(0)$ \\
\hline B (BPL) & N/A & $6(24)$ & $1(4)$ & $7(28)$ \\
\hline C (CC) & $1(4)$ & N/A & $3(12)$ & N/A \\
\hline E* $^{*}$ (EES-E) & $2(8)^{*}$ & $0(0)$ & $0(0)$ & $0(0)$ \\
\hline
\end{tabular}

In the SDL System, we abbreviated the Petersen (retro alimentary limb) and Brolin (retro enteroenterostomy) space as $P$ and $B$, named the direction of right to left as $L$, left to right as $R$, and defined the alimentary limb, biliopancreatic limb, common channel, enteroenterostomy/emergency as $A, B, C, E$ respectively. N/A: theoretically impossible. *Emergency.

derstanding and communication of internal hernia information, but also in accurate evaluation of the severity, and could be used in evaluation of bariatric operation series.

Certainly, the posterior colonic approach was not included in our system, but the retro transversal Roux-en-Y reconstruction is seldom performed by laparoscopic surgery. There are more complicated situations not detected in our series, but they could be described using the SDL system. The rate of internal herniation in our institute leads to a concern that internal herniation complication is often also after systematic mesentery closure. We do hope SLD classification system will be useful in clinical application.

\section{Conflict of interest}

The authors declare no conflict of interest.

\section{References}

1. Petersen W. [Ueberdarmveschlingung nach der gastro-enterostomie]. Arch Klin Chir 1900; 62: 94-114.

2. Podnos YD, Jimenez JC, Wilson SE, et al. Complication after laparoscopic gastric bypass: a review of 3464 case. Arch Surg 2003; 138: 957-61.

3. Steele KE, Prokopowicz GP, Magnuson T, et al. Laparoscopic antecolic Roux-en-Y gastric bypass with closure of internal defects leads to fewer internal hernias than the retrocolic approach. Surg Endosc 2008; 22: 2056-61.

4. Mickevicius A, Sufi P, Heath D. Factors predicting the occurrence of a gastrojejunal anastomosis leak following gastric bypass. Videosurgery Miniinv 2014; 9: 436-40.

5. Garza E Jr, Kuhn J, Arnold D, et al. Internal hernias after laparoscopic Roux-en-Y gastric bypass. Am J Surg 2004; 188: 796-800. 
6. Higa KD, Boone KB, Ho T. Complications of the laparoscopic Roux-en-Y gastric bypass: 1040 patients: what have we learned? Obes Surg 2000; 10: 509-13.

7. Karcz WK, Karcz-Socha I, Kuesters S, et al. Duodeno-entero omega switch with gastric plication - more physiological technique in metabolic surgery. J Videosurg 2013; 8: 273-9.

8. Petersen H. [Treitz'shernia with total incarceration of the small intestine]. Zentralbl Chir 1972; 97: 1112-5.

9. Brolin RE. The antiobstruction stitch in stapled Roux-en-Y enteroenterostomy. Am J Surg 1995; 169: 355-7.

10. Brolin RE. Hernias after bariatric surgery. In: Principles of metabolic surgery. Karcz WK, Thomush O (eds.). Springer 2012.

11. Higa KD, Ho T, Boone KB. Internal hernias after laparoscopic Roux-en- $Y$ gastric bypass: incidence, treatment and prevention. Obes Surg 2003; 13: 350-4.

12. Meyer A, Nowotny K, Poeschl M. Internal hernias of the ileocecal region. Ergeb Chir Orthop 1963; 44: 176-204.

13. Grubnik VV, Grubnik AV, Vorotyntseva KO. Laparoscopic repair of incisional and ventral hernias with the new type of meshes: randomized control trial. Videosurgery Miniinv 2014; 9: 145-51.

14. Champion JK, Williams M. Small bowel obstruction and internal hernias after laparoscopic Roux-en-Y gastric bypass. Obes Surg 2003; 13: 596-600.

15. Rodriguez A, Mosti M, Sierra M, et al. Small bowel obstruction after antecolic and antegastric laparoscopic Roux-en-Y gastric bypass: could the incidence be reduced? Obes Surg 2010; 20: 1380-4.

16. O'Rourke RW. Management strategies for internal hernia after gastric bypass. J Gastrointest Surg 2011; 15: 1049-54.

17. Gaszynski T, Szewczyk T. The influence of laparoscopic vs. open gastric bypass on hemodynamic function in morbidly obese patients during general anesthesia. Videosurgery Miniinv 2014; 9: 83-8.

18. Koppman JS, Li C, Gandsas A. Small bowel obstruction after laparoscopic Roux-en-Y gastric bypass: a review of 9,527 patients. J Am Coll Surg 2008; 206: 571-84.

19. Lannelli A, Facchiano E, Gugenheim J. Internal hernia after laparoscopic Roux-en-Y gastric bypass for morbid obesity. Obes Surg 2006; 16: 1265-71.

20. Mickevicius A, Sufi P, Heath D. Factors predicting the occurrence of a gastrojejunal anastomosis leak following gastric bypass. Videosurgery Miniinv 2014; 9: 436-40.

21. Tucker ON, Escalante-Tattersfield T, Szomstein S, Rosenthal RJ. The ABC System: a simplified classification system for small bowel obstruction after laparoscopic Roux-en-Y gastric bypass. Obes Surg 2007; 17: 1549-54.

Received: 9.03.2015, accepted: 30.03.2015. 